\title{
The Mini-Addenbrooke's Cognitive Examination (M-ACE) as a brief cognitive screening instrument in Mild Cognitive Impairment and mild Alzheimer's disease
}

\author{
Diane da Costa Miranda ${ }^{1}$, Sonia Maria Dozzi Brucki ${ }^{1}$, Mônica Sanches Yassuda
}

\begin{abstract}
The Mini-Addenbrooke's Cognitive Examination (M-ACE) is a brief cognitive screening test that evaluates four main cognitive domains (orientation, memory, language and visuospatial function) with a maximum score of 30 points and administration time of five minutes. Objective: To assess the performance of healthy elderly, MCl patients and mild AD patients using the Brazilian version of the M-ACE. Methods: The test was applied to a group of 36 Mild Cognitive Impairment (MCl), 23 mild Alzheimer's Disease (AD) and 25 cognitive healthy elderly. All participants were aged $\geq 60$ years. Results: The M-ACE displayed high internal consistency (Cronbach alpha $>0.8 ; 95 \% \mathrm{Cl} 0.7-0.8$ ) and proved effective for differentiating the $\mathrm{AD}$ group from $\mathrm{MCl}$ and control groups, providing superior accuracy than the MMSE (the cut-off point of 20 points had the highest sensitivity and specificity $-95.6 \%$ and $90.16 \%$ respectively, with a high area under the curve $-\mathrm{AUC}=0.8 ; 95 \% \mathrm{Cl} 0.7-0.9$ ). Performance on the M-ACE was strongly correlated with that of the MMSE and Functional Activities Questionnaire (FAQ). The M-ACE was not accurate in discriminating MCI from control subjects. Conclusion: The M-ACE is a brief screening test which provided high accuracy for diagnosing AD in this sample. The suggested cut-off point in this study was 20 points for AD.
\end{abstract}

Key words: dementia, cognition, Alzheimer's disease, cognitive dysfunction, neuropsychological tests, Brazil.

MINI-ADDENBROOKE'S COGNITIVE EXAMINATION (M-ACE) COMO INSTRUMENTO DE AVALIAÇÃO COGNITIVA BREVE NO COMPROMETIMENTO COGNITIVO LEVE E DOENÇA DE ALZHEIMER LEVE

RESUMO. A Mini-Addenbrooke's Cognitive Examination (M-ACE) consiste em um teste de avaliação cognitiva breve composta de cinco itens que visam avaliar quatro domínios cognitivos principais (orientação, memória, linguagem e função visoespacial) com pontuação máxima de 30 pontos e um tempo de administração de cinco minutos. Objetivo: Avaliar o desempenho de idosos cognitivamente saudáveis, com CCL e DA leve na versão brasileira da M-ACE. Métodos: 0 teste foi aplicado em um grupo de 23 sujeitos com DA provável leve, 36 CCL e 25 idosos cognitivamente saudáveis. Todos os participantes incluídos tinham idade $\geq 60$ anos. Resultados: A M-ACE apresentou alta consistência interna (alfa de Cronbach >0,8; IC 95\% 0,7 a 0,8) e mostrou-se capaz de diferenciar o grupo DA dos demais participantes, com uma acurácia superior ao MEEM. 0 ponto de corte de 20 pontos foi 0 de maior sensibilidade e especificidade (95,6\% e 90,16\% respectivamente) para diferenciar DA dos outros dois grupos, com área sob a curva considerada alta (ASC=0,8; IC 95\% 0,7-0,9). A M-ACE apresentou forte correlação com MEEM e Questionário de Atividades Funcionais (QAF). M-ACE não apresentou boa acurácia para diferenciar CCL do grupo controle. Conclusão: A M-ACE pode ser considerada um teste rápido de rastreio com elevada acurácia no diagnóstico de DA nessa amostra. 0 ponto de corte sugerido neste estudo é de 20 pontos para DA.

Palavras-chave: demência, cognição, doença de Alzheimer, disfunção cognitiva, testes neuropsicológicos, Brasil.

\footnotetext{
This study was conducted at the Departamento de Neurologia, Faculdade de Medicina, Universidade de São Paulo, São Paulo, SP, Brazil.

'Grupo de Neurologia Cognitiva e do Comportamento (GNCC), Departamento de Neurologia, Faculdade de Medicina, Universidade de São Paulo, São Paulo, SP, Brazil.
}

Diane da Costa Miranda. Universidade de São Paulo - Av. Dr. Enéas de Carvalho Aguiar, 255 - 05403-000 São Paulo SP - Brazil. E-mail: dianemiranda@usp.br

Disclosure: The authors report no conflicts of interest.

Received April 12, 2018. Accepted in final form November 01, 2018.

(c) BY 
C gnitive assessment is fundamental for diagnosis and follow-up of Alzheimer's Disease (AD) and other dementias, as well as Mild Cognitive Impairment (MCI). In clinical practice, high patient caseloads and limited time available for consultations preclude the use of time-consuming tests in individuals with cognitive complaints. Hence, a screening test for early diagnosis is important in yielding information and allowing the provision of social and psychological support as well as best care and intervention. ${ }^{1,2}$

The Mini-Addenbrooke's Cognitive Examination (M-ACE) is a five-item scale: time orientation, learning and recall of name and address, verbal fluency for animals and the clock drawing test (CDT), designed to assess four main cognitive domains: orientation, memory, language and visuospatial function, with a maximum score of 30 points and administration time of five minutes. The validation study of the scale revealed higher sensitivity than the Mini-Mental State Exam (MMSE) across all cut-off points. ${ }^{3}$

Given the importance of cognitive assessment for diagnosing $\mathrm{AD}$ and $\mathrm{MCI}$ and the paucity of brief cognitive screening instruments validated for use in Brazil, the objective of the present study was to assess the performance of healthy elderly, MCI patients and AD patients using the Brazilian version of the M-ACE.

\section{METHODS}

\section{Participants}

Twenty-three subjects with $\mathrm{AD}$ and 36 with $\mathrm{MCI}$ were recruited from the Neurology clinic and from the Referral Center for Cognitive Disorders of University (CEREDIC) of São Paulo. Probable AD was diagnosed based on the criteria of the National Institute on Aging and Alzheimer's Association ${ }^{4}$ and classified as mild according to final score one on the Clinical Dementia Rating (CDR). ${ }^{5}$ The diagnosis of MCI was defined using the criteria of Petersen. ${ }^{6}$ The control group comprised elderly without cognitive complaints recruited from the community that scored $<2$ on the Functional Activities Questionnaire (FAQ) ${ }^{7}$ and greater than the educationadjusted median on the $\mathrm{MMSE}^{8}$ (illiterate=20 points; $1-4$ years of education $=25$ points; $5-8$ years $=26$ points; 9-11 years $=28$ points; $>11$ years $=29$ points), ${ }^{9}$ and $\geq 7$ on the memory recall of the Brief Cognitive Screening Battery (BCSB). ${ }^{10}$ Only participants aged $\geq 60$ years were eligible for inclusion.

All participants gave written consent. In the case of illiterate individuals or those with dementia, the form was signed by an accompanying family member or guardian.
The study was approved by the Research Ethics Committee of the Hospital das Clinicas da Faculdade de Medicina da Universidade de São Paulo.

\section{Brazilian version of the M-ACE}

The original version of the M-ACE was adapted based on the Brazilian version of the ACE-R, previously translated and validated for the Brazilian population. ${ }^{11}$ However, the original M-ACE has three versions (A, B and $C$ ) for longitudinal monitoring; the only difference is in name and address of the memory item. Therefore, it was necessary to create new names and addresses for the other two versions ( $B$ and $C$ ). This was initially carried out by two specialists in cognition by replicating the same format as the original version (name and surname, street with double name, followed by number, city and state). The adapted versions were established after a pilot study, in which they were applied to 15 healthy individuals, aged $>60$ years with different educational levels to assess its applicability and determine the need for refinements. Version A used the names and addresses from the ACE-R, "Renato Moreira, Rua Bela Vista 73, Santarém Pará", version B: "Antonio Siqueira, Rua Porto Alegre 53, Londrina, Paraná" and version C: "Marcelo Silveira, Rua Porto Feliz 83, Santana, Amapá". (Supplement).

\section{Procedures}

Individuals that met the inclusion criteria were assessed between October 2015 and November 2016. All participants were submitted to anamnesis, neurological examination and a test battery including the MMSE, BCSB, FAQ and the Brazilian version of the M-ACE (versions $\mathrm{A}, \mathrm{B}$ and $\mathrm{C}$ ).

\section{Statistical analysis}

The Chi-square test was employed to compare the categorical variables between diagnostic groups. One-way ANOVA and Kruskal-Wallis tests were employed to compare the numerical variables. Spearman's correlation coefficient was used to analyze the relationship between M-ACE scores and the other variables assessed. Values close to +1 indicate strong correlation among values, whereas values close to 0 show an absence of relationship among the variables. ${ }^{12}$ Cronbach's alpha coefficient, an indicator of internal reliability, was used to analyze the internal consistency of the M-ACE and its three versions. Alpha values $\geq 0.60$ indicate moderate consistency, whereas values $\geq 0.70$ indicate high consistency. ${ }^{13}$ The diagnostic accuracy of the M-ACE, identification of the best cut-off scores for sensitivity/speci- 
Table 1. Demographic data and performance on the cognitive tests.

\begin{tabular}{|c|c|c|c|c|c|}
\hline & Total $(n=84)$ & Control $(n=25)$ & $\operatorname{MCl}(n=36)$ & $A D(n=23)$ & p-value \\
\hline Female, n (\%) & $57(67.8)$ & $15(60)$ & $30(83.3)$ & $12(52.2)$ & $0.028^{a}$ \\
\hline Age, mean (SD) & $73(7.4)$ & $70(6.9)$ & $72(6.8)$ & $77(7.5)$ & $0.003^{b}$ \\
\hline Education, mean (SD) & $11(5.6)$ & $12(5.5)$ & $11(5.3)$ & $9(5.7)$ & $0.078^{c}$ \\
\hline M-ACE, mean (SD) & $22(6.4)$ & $26(3.4)$ & $25(3.4)$ & $14(4.7)$ & $<0.001^{c}$ \\
\hline MMSE, mean (SD) & $26(3.3)$ & $28(2.1)$ & $27(1.7)$ & $22(3.6)$ & $<0.001^{\mathrm{c}}$ \\
\hline BCSB DR, mean (SD) & $7(2.5)$ & $8(0.9)$ & $8(1.5)$ & $4(2.4)$ & $<0.001^{\mathrm{c}}$ \\
\hline $\mathrm{FAQ}^{1}$ & $3(5.6)$ & $0(0.2)$ & $0(0.7)$ & $10(6.5)$ & $<0.001^{c}$ \\
\hline
\end{tabular}

SD: Standard Deviation; MCI: Mild Cognitive Impairment; AD: Alzheimer's Disease; M-ACE: Mini-Addenbrooke's Cognitive Examination; MMSE: Mini-Mental State Exam; BCSB DR: Brief Cognitive Screening Battery - Delayed Recall; FAQ: Functional Activities Questionnaire; ${ }^{1}$ Higher scores indicate poorer functional performance; ${ }^{\mathrm{a} C h i-s q u a r e ~ t e s t ; ~}{ }^{\mathrm{D}}$ One-way ANOVA; ${ }^{\mathrm{C} K r u s k a l-W a l l i s ~ T e s t . ~}$

Table 2. Sensitivity, specificity, PPV, NPV of the M-ACE versus MMSE (AD versus $\mathrm{MCl}$ and Control).

\begin{tabular}{ccc}
\hline & M-ACE & MMSE \\
\hline Sensitivity & 95.65 & 91.30 \\
\hline Specificity & 90.16 & 80.33 \\
\hline PPV & 78.57 & 63.64 \\
\hline NPV & 98.21 & 96.08 \\
\hline Accuracy & 91.67 & 83.33 \\
\hline Cut-off point & 20 & 26 \\
\hline AUC $(95 \%$ Cl) & $0.805(0.70-0.90)$ & $0.726(0.61-0.83)$ \\
\hline
\end{tabular}

Metric: Youden Index; PPV: Positive predictive value; NPV: Negative predictive value; AUC: Area under the curve; Cl: Confidence interval.

ficity and the positive/negative predictive values of each of the measures were derived using the Receiver Operating Curves (ROC curves) method. The data were analyzed using the R 3.4 .3 statistics software program. The level of significance adopted for the statistical tests was $5 \%$, corresponding to a $\mathrm{p}$-value $<0.05$.

\section{RESULTS}

Demographic data and performance on the main cognitive tests are summarized in Table 1 . Mean age of the participants was $73 \pm 7.4$ years. Overall, females predominated in the groups (67.8\%). Mean education was $11 \pm 5.6$ years. The $A D$ group had worse performance on all cognitive tests compared with both the $\mathrm{MCI}$ and control groups. There was a difference in age and sex between the groups. Regarding education, the three groups were similar.

The M-ACE displayed high internal consistency (Cronbach alpha $=0.8$, 95\% CI 0.776-0.869), and high accuracy for differentiating the $\mathrm{AD}$ group from the

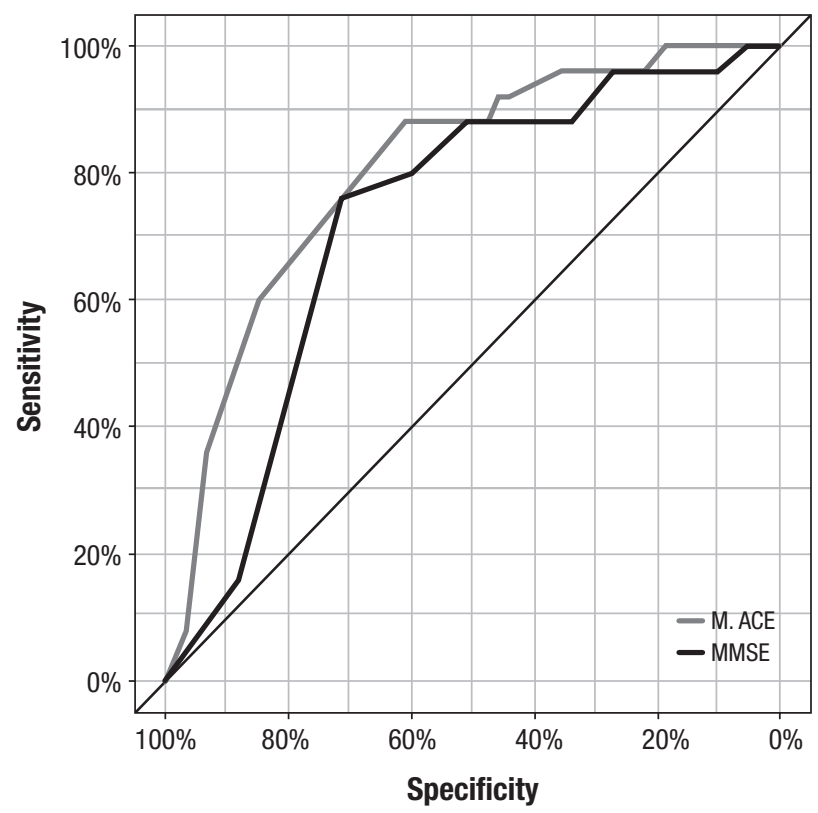

Figure 1. M-ACE and MMSE ROC Curves for differentiating the AD group from the other groups $(\mathrm{MCl}+$ Control).

other groups ( $\mathrm{MCI}+$ Control), with greater area under the curve than the MMSE (Table 2, Figure 1).

In terms of differentiating controls from MCI, both the M-ACE and MMSE showed low accuracy (Table 3, Figure 2). On the analysis of the confusion matrix, overall, the M-ACE had slightly better performance in discriminating the three groups compared with the MMSE (Tables 4 and 5)

On the correlation analysis, the M-ACE showed a negative correlation with age $(-0.3,95 \% \mathrm{CI}=-0.5-[-0.1]$, $\mathrm{p}<0.001)$ and positive with education $(0.4,95 \% \mathrm{CI}=0.2-$ $0.5, \mathrm{p}<0.001)$ and strong correlation with the MMSE $(0.7,95 \% \mathrm{CI}=0.6-0.8, \mathrm{p}<0.001)$ and FAQ $(-0.7,95 \% \mathrm{CI}=$ $-0.8-[-0.6], \mathrm{P}<0.001)$. 


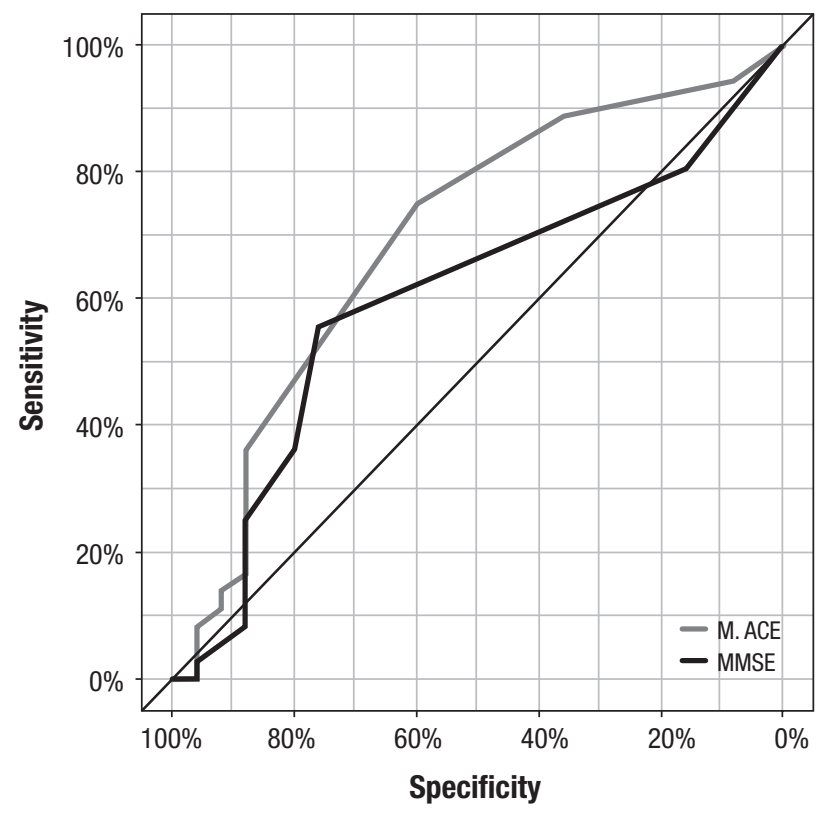

Figure 2. M-ACE and MMSE ROC Curves for differentiating control group from $\mathrm{MCl}$ group.

\section{DISCUSSION}

The M-ACE demonstrated easy application and good acceptability among the participants. Mean administration time of the test in the sample studied was five minutes $( \pm 2)$, the same as that reported for the original version.

The M-ACE proved effective for differentiating the $\mathrm{AD}$ group from the other groups and provided superior accuracy to the MMSE. The cut-off point of 20 points had the highest sensitivity and specificity for AD diagnosis. The M-ACE showed high reliability, indicating that all components of its score contribute to the cognitive assessment.

These results are similar to those of the validation study of the Spanish version of the M-ACE conducted in Barcelona with a sample of 175 individuals aged > 65 years. In the study, a cut-off point of 16 was defined for
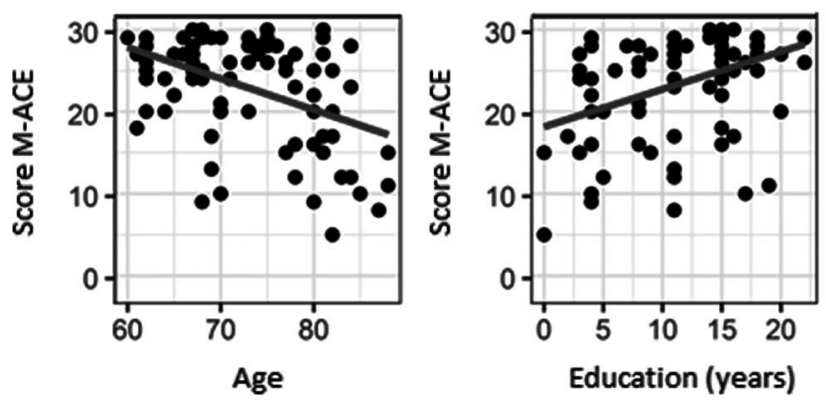

Table 3. Sensitivity, specificity, PPV, NPV of the M-ACE versus MMSE (control versus MCl).

\begin{tabular}{ccc}
\hline & M-ACE & MMSE \\
\hline Sensitivity & 75 & 55.56 \\
\hline Specificity & 60 & 76 \\
\hline PPV & 72.97 & 76.92 \\
\hline NPV & 62.50 & 54.29 \\
\hline Accuracy & 68.85 & 63.93 \\
\hline Cut-off point & 27 & 28 \\
\hline AUC $(95 \%$ Cl) & $0.69(0.55-0.83)$ & $0.60(0.45-0.74)$ \\
\hline
\end{tabular}

Metric: Youden Index; PPV: Positive predictive value; NPV: Negative predictive value; AUC: Area under the curve; Cl: Confidence interval.

Table 4. Confusion matrix for M-ACE.

\begin{tabular}{cccccc}
\hline & & \multicolumn{4}{c}{ Predicted } \\
\cline { 2 - 6 } & AD & MCI & Control & Total \\
\hline \multirow{2}{*}{ 즐 } & AD & $\mathbf{2 2}$ & 1 & 0 & 23 \\
\cline { 2 - 6 } & MCl & 4 & $\mathbf{2 3}$ & 9 & 36 \\
\cline { 2 - 6 } & Control & 2 & 8 & $\mathbf{1 5}$ & 25 \\
\cline { 2 - 6 } & Total & 28 & 32 & 24 & $\mathbf{8 4}$ \\
\hline
\end{tabular}

Global accuracy ${ }^{*}=71.43 \%$. ${ }^{*}$ bbtained by dividing total correct classifications (sum of main diagonal) by total number of participants.

Table 5. Confusion matrix for MMSE.

\begin{tabular}{cccccc}
\hline & \multicolumn{5}{c}{ Predicted } \\
\cline { 2 - 6 } & & AD & MCI & Control & Total \\
\hline \multirow{2}{*}{ 졸 } & AD & $\mathbf{2 1}$ & 1 & 1 & 23 \\
\cline { 2 - 6 } & MCl & 9 & $\mathbf{1 1}$ & 16 & 36 \\
\cline { 2 - 6 } & Control & 3 & 3 & $\mathbf{1 9}$ & 25 \\
\cline { 2 - 6 } & Total & 33 & 15 & 36 & $\mathbf{8 4}$ \\
\hline
\end{tabular}

Global accuracy ${ }^{*}=60,71 .{ }^{*}$ Obtained by dividing total correct classifications (sum of main diagonal) by total number of participants.
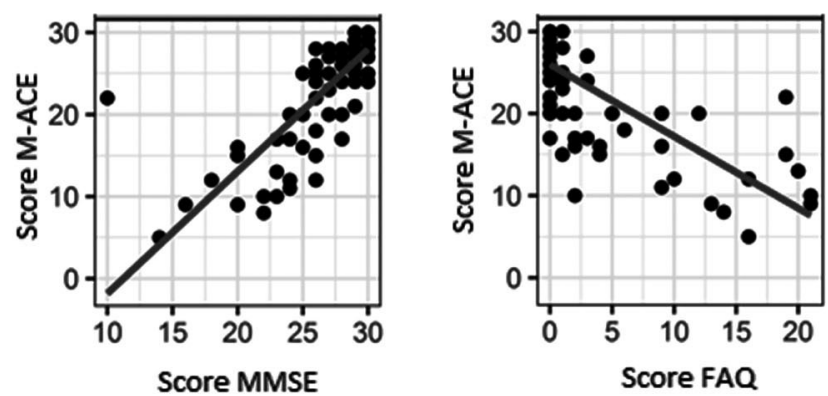

Figure 3. Scatter plots of M-ACE for age, education, MMSE and FAQ. 
dementia, with sensitivity of $86.7 \%$, specificity of $87 \%$ and $A U C=0.94$, and provided better discrimination rates than the MMSE (cut-off $\leq 24$; sensitivity=88.0; specificity=78.3). The test also had high internal consistency (Cronbach alpha $=0.828) .{ }^{14}$

These results support the fact that, although the MMSE is the most widely used screening instrument, it has several limitations. One of these limitations is that executive function is not well assessed by the instrument, being the first (sometimes only) symptom to present in many cases of dementia syndrome. In addition, the MMSE has overly simple tasks for memory and language functions which fail to detect early deficits. ${ }^{15,16}$

In the $\mathrm{M}-\mathrm{ACE}$, the inclusion of the memory component (repetition and recall of name and address) reflects the importance of episodic memory impairment in early detection of $\mathrm{AD}$. The M-ACE also includes the verbal fluency (animals category) test, which relies on frontal executive function and also assesses semantic memory. The incorporation of the clock drawing test (CDT) in the M-ACE further broadens its ability to analyze cognitive profile, since it assesses memory, motor function, executive function and verbal comprehension. ${ }^{16,17}$

In this study, the accuracy of the M-ACE in diagnosing $\mathrm{MCI}$ was poor. Validation studies of screening tests for $\mathrm{MCI}$ are scarce. A systematic review and meta-analysis pooled data in the literature on the performance of the main brief screening tests found that the MMSE had combined sensitivity and specificity of 0.62 and 0.87 , respectively; the MoCA had sensitivity of 0.89 and specificity of 0.75 ; and the Mini-Cog sensitivity of 0.91 and specificity of 0.86 . However, these results are limited because the ideal approach is to directly compare the screening tests in the same group of participants with similar educational levels. ${ }^{18}$

The MoCA is the most described and used test for screening MCI. ${ }^{19,20}$ A prospective study directly comparing the accuracy of the M-ACE with the MoCA found that both tests had good sensitivity for diagnosing dementia and MCI, a high negative predictive value, but low specificity and a positive predictive value (sensitivity of M-ACE for dementia=0.98 and $\mathrm{MCI}=0.95$. Sensitivity of the MoCA for dementia $=1.00$ and $\mathrm{MCI}=0.92$ ). On the analysis of the ROC curve, both showed good accuracy for dementia (AUC M-ACE $=0.90$ [0.87-0.93], AUC MoCA=0.91 [0.89-0.93]), where the MoCA was slightly superior to the M-ACE for detecting MCI (AUC M-ACE $=0.78$ [0.75-0.81], AUC MoCA=0.82 [0.79-0.85]). ${ }^{21}$

On the analysis of correlation of the M-ACE with demographic variables, there was positive correlation of education with total score on the M-ACE. An expected finding given that most cognitive tests are vulnerable to educational bias, an influence that is greater in countries with high levels of illiteracy and low education among elderly, such as Brazil. ${ }^{22}$ Analysis of the correlation of M-ACE with other cognitive tests revealed a strong correlation with the MMSE, confirming its criterion validity.

Limitations of the present study include the fact that no measurements of test stability (intra-examiner and inter-examiner) were performed. In addition, this was a preliminary assessment of the M-ACE, and application of the test in different samples is necessary.

In summary, the M-ACE is a brief screening test that provided high accuracy for diagnosing $A D$ in this sample, but was not accurate in discriminating patients with MCI from control subjects, where more studies evaluating its performance in this group are needed.

Compared with the MMSE, the M-ACE has advantages not only regarding its psychometric properties, but also in defining cognitive profile. The test is also freely available, unlike the MMSE, whose copyright belongs to Psychological Assessment Resources, limiting its application, especially in research settings.

The M-ACE should be compared against other brief tests reported in the literature, such as the CASI-S and Mini-Cog, to further validate the instrument.

Author contributions. All the authors have contributed to the manuscript preparation and conceptualization.

\section{REFERENCES}

1. Prince M, Bryce R, Ferri C. World Alzheimer Report 2011 The benefits of early diagnosis and intervention. https://www.alz.co.uk/research/WorldAlzheimerReport2011.pdf

2. Waldemar G, Dubois B, Emre M, Georges J, McKeith IG, Rossor M, et al. Recommendations for the diagnosis and management of Alzheimer's disease and other disorders associated with dementia: EFNS guideline. Eur J Neurol. 2007;14(1):1-26.

3. Hsieh S, McGrory S, Leslie F, Dawson K, Ahmed S, Butler CR, et al. The mini-addenbrooke's cognitive examination: A new assessment tool for dementia. Dement Geriatr Cogn Disord. 2015;39:1-11.
4. McKhann G, Knopman DS, Chertkow H, Hymann B, Jack CR, Kawas $\mathrm{C}$, et al. The diagnosis of dementia due to Alzheimer's disease: Recommendations from the National Institute on Aging- Alzheimer's Association workgroups on diagnostic guidelines for Alzheimer's disease. Alzheimers Dement. 2011;7(3):263-9.

5. Morris JC. The Clinical Dementia Rating (CDR): Current version and scoring rules. Neurology. 1993;43(11):2412.

6. Petersen RC. Mild cognitive impairment as a diagnostic entity. J. Intern. Med. 2004;256(3):183-94.

7. Pfeffer RI, Kurosaki T, Harrah $\mathrm{CH}$, Chance JM, Filos S. Measurement 
of Functional Activities in Older Adults in the Community. J Gerontol. 1982;37(3):323-9.

8. Folstein MF, Folstein SE, McHugh PR. "Mini-mental state". A practical method for grading the cognitive state of patients for the clinician. J Psychiatr Res. 1975;12(3):189-98.

9. Brucki SMD, Nitrini $R$, Caramelli $P$, Bertolucci PHF, Okamoto $\Vdash H$. Sugestões para o uso do mini-exame do estado mental no Brasil. Arq Neuropsiquiatr. 2003;61(3 B):777-81.

10. Nitrini R, Lefèvre BH, Mathias SC, Caramelli P, Carrilho PE, Sauaia N, et al. Testes neuropsicológicos de aplicação simples para o diagnóstico de demência. Arq Neuropsiquiatr. 1994;52(4):457-65.

11. Amaral-Carvalho V, Caramelli P. Brazilian adaptation of the Addenbrooke's Cognitive Examination-Revised (ACE-R). Dement Neuropsychol 2007; 1(2):212-6.

12. Finney DJ. Statistics for biologists Chapman and Hall. London New York; 1980;

13. Cronbach LJ. Coefficient alpha and the internal structure of tests. Psychometrika. 1951;16(3):297-334

14. Matias-Guiu JA, Fernandez-Bobadilla R. Validación de la versión española del Mini-Addenbrooke's Cognitive Examination para el cribado de demencias. Neurologia. 2016;31(9):646-648.

15. Aprahamian I, Rasslan Z. Rastreio Cognitivo em Idosos para o Clínico. Rev Soc Bras Clin Méd. 2008;6:254-9.
16. Mathuranath PS, Nestor PJ, Berrios GE. A brief cognitive test battery to differentiate Alzheimer's disease and frontotemporal dementia Neurology. 2010;55:1613-20.

17. Montiel JM, Cecato JF, Bartholomeu D, Martinelli JE. Testes do desenho do relógio e de fluência verbal: contribuição diagnóstica para o Alzheimer. Rev Psicol Teor Prát. 2014;16(1):169-80.

18. Tsoi KKF, Chan JYC, Hirai HW, Wong SYS, Kwok TCY. Cognitive Tests to Detect Dementia: A Systematic Review and Meta-analysis. JAMA Intern Med. 2015;175(9):1450-8.

19. Memória CM, Yassuda MS, Nakano EY, Forlenza O V. Brief screening for mild cognitive impairment: Validation of the Brazilian version of the Montreal cognitive assessment. Int J Geriatr. Psychiatry. 2013; 28(1): 34-40.

20. Smith T, Gildeh N, Holmes C. The Montreal Cognitive Assessment: validity and utility in a memory clinic setting. Can J Psychiatry. 2007; 52(5):329-32.

21. Larner AJ. MACE versus MoCA: Equivalence or superiority? Prag matic diagnostic test accuracy study. Int. Psychogeriatrics. 2017;29(6): 931-7.

22. Yassuda MS, Diniz BSO, Flaks MK, Viola LF, Pereira FS, Nunes PV, et al. Neuropsychological profile of brazilian older adults with heterogeneous educational backgrounds. Arch Clin Neuropsychol. 2009;24(1): $71-9$ 